\title{
Shifting perspectives: A comparison of travel-time-based and carbon-based accessibility landscapes
}

\author{
Julia Kinigadner \\ Technical University of Munich \\ julia.kinigadner@tum.de \\ Benjamin Büttner \\ Technical University of Munich \\ benjamin.buettner@tum.de
}

\author{
David Vale \\ University of Lisbon \\ dvale@fa.ulisboa.pt \\ Gebhard Wulfhorst \\ Technical University of Munich \\ gebhard.wulfhorst@tum.de
}

\begin{abstract}
Undoubtedly, climate change and its mitigation have emerged as main topics in public discourse. While accessibility planning is recognized for supporting sustainable urban and transport development in general, the specific challenge of reducing transportrelated greenhouse gas emissions has rarely been directly addressed. Traditionally, accessibility is operationalized in line with the user perception of the transport system. Travel-time-based measures are considered to be closely linked with travel behavior theory, whereas $\mathrm{CO}_{2}$ emissions are not necessarily a major determinant of travel decisions. Given the changed prioritization of objectives, additional emphasis should be placed on the environmental costs of travel rather than solely the user costs. Accessibility analysis could account for this shift in perspectives by using $\mathrm{CO}_{2}$ emissions instead of travel time in the underlying cost function. While losing predictive power in terms of travel behavior compared to other implementations of accessibility, carbon-based accessibility analysis enables a normative understanding of travel behavior as it ought to be. An application in the Munich region visualizes the differences between travel-time-based and carbonbased accessibility by location, transport mode, and specification of the accessibility measure. The emerging accessibility landscapes illustrate the ability of carbon-based accessibility analysis to provide new insights into land use and transport systems from a different perspective. Based on this exercise, several use cases in the context of low-carbon mobility planning are discussed and pathways to further develop and test the method in cooperation with decision-makers are outlined.
\end{abstract}

\section{Article history:}

Received: February 21, 2020

Received in revised form: May

11,2020

Accepted: August 8, 2020

Available online: March 15,

2021

\section{Introduction}

Increasing awareness of the negative and potentially irreversible consequences of global warming has caused the hierarchy of planning objectives to be reconsidered. Emission reductions in all sectors have become a top priority for governments around the globe (UNFCCC, 2015). The transport sector struggles most to achieve emission reduction targets and - in contrast to other sectors - has not suc-

Copyright 2021 Julia Kinigadner, David Vale, Benjamin Büttner \& Gebhard Wulfhorst http://dx.doi.org/10.5198/jtlu.2021.1741

ISSN: 1938-7849 | Licensed under the Creative Commons Attribution - Noncommercial License 4.0

The Journal of Transport and Land Use is the official journal of the World Society for Transport and Land Use (WSTLUR) and is published and sponsored by the University of Minnesota Center for Transportation Studies. 
ceeded in decreasing emissions (EEA, 2019; US EPA, 2019). Environmental objectives seem to be in conflict with the social and economic benefits linked to mobility (Banister, 2011). Accessibility, determined by the joint characteristics of the land use and transport systems, could be a suitable concept to address this challenge.

The first reason for employing accessibility to plan for low carbon mobility options is its intrinsic capability to integrate land use and transport planning. Dense and mixed use urban development can contribute to the goal of greenhouse gas emission reductions, especially if oriented towards public transport systems (Banister, 2011; Schwanen, Banister, \& Anable, 2011). Thus, consideration of land use configurations and policies is indispensable in promoting sustainable transport (Loo \& Tsoi, 2018). Increased vehicle efficiency will not solve the issue of transport-related emissions if separation of urban functions, suburbanization, and car dependence prevail (Chapman, 2007). Multimodal mobility behavior, increasingly enabled by innovative mobility services, will not suffice if the level of travel activity, in particular trip distance, continues to grow (Heinen \& Mattioli, 2019). Through the introduction of a land use dimension, accessibility helps to distinguish between the need to reach opportunities as an end and the need to travel as a means.

Tackling climate change requires efforts on multiple scales, from local to global (Marsden, Ferreira, Bache, Flinders, \& Bartle, 2014; Ostrom, 2010), and depends on the involvement and interaction of multiple actors (Geels, 2012). In order to reduce transport-related emissions, not only the impacts of potential interventions and policies need to be assessed, but also the issue of implementation needs to be addressed (Lewis, Zako, Biddle, \& Isbell, 2018). Even if political decision-makers have succeeded in defining a suitable framework for low carbon mobility, public awareness, acceptance, and commitment are equally important (Banister, 2008). Against this background, the second reason for exploring accessibility-based planning approaches to address climate change is their ability to support decision-making on multiple levels, both spatially and institutionally. Firstly, accessibility analysis is applicable on various geographical planning scales (Papa, Silva, Te Brömmelstroet, \& Hull, 2016). Secondly, accessibility can - given an appropriate implementation - contribute to enhancing discussion and decision-making of stakeholders across different institutions, disciplines, and levels of expertise (Te Brömmelstroet, Curtis, Larsson, \& Milakis, 2016; Wulfhorst, Büttner, \& Ji, 2017). Complex tools might be needed for further in-depth analysis, but simpler tools, featuring high transparency and communication value, are most suitable to explore alternative scenarios in strategic planning (Ford, Dawson, Blythe, \& Barr, 2018; Te Brömmelstroet, 2010). While the underlying accessibility metrics might be of varying complexity, accessibility instruments often produce visual outputs in map format (Papa et al., 2016), which tend to improve understandability and communicability (Büttner, Ji, \& Wulfhorst, 2019; Curtis \& Scheurer, 2010).

This potential is not yet fully exploited, since emissions are seldom explicitly considered in accessibility analysis and planning. Environmental objectives are often addressed indirectly, for example when trying to minimize the gap between accessibility by car and accessibility by other modes that are considered to be more sustainable (Salonen $\&$ Toivonen, 2013). Accessibility measures in these and many other applications are based on the uses and perceptions of the people. Consequently, travel costs are operationalized as internal user costs, typically represented by travel time (Cui \& Levinson, 2018). In contrast, emissions are not necessarily a major determinant of individual travel decisions, but represent a normative, politically defined constraint to travel activities. The plea for reinventing seemingly invariable concepts, thus enabling new rather than habitual ways of thinking in the context of climate change (Schwanen, 2019), might as well be transferred to the accessibility concept. In this paper, we propose an alternative conceptualization of accessibility, dominated by an environmental perspective instead of a user perspective. More precisely, travel time is replaced by $\mathrm{CO}_{2}$ emissions as the relevant travel cost. Mul- 
tiple studies have compared accessibility implementations based on different cost components (Büttner, 2017; Cui \& Levinson, 2018; El-Geneidy et al., 2016), impedance functions (Higgins, 2019; Vale \& Pereira, 2016), behavioral foundations (Páez, Scott, \& Morency, 2012) or indicator types (Kwan, 1998). However, to the best of our knowledge, the partially conflicting perspectives of the user and the environment have never been directly compared. In order to determine whether this reinvention provides new insights compared to traditional implementations, both approaches are compared and contrasted using the Munich region as a case study. A review of the theoretical considerations underlying the accessibility concept and its operationalization follows in section 2, the presentation of the implementations in section 3, and a discussion of the application potential of carbon-based accessibility in section 4. Conclusions and future research paths are outlined in section 5.

\section{Perspectives on accessibility}

In this paper, accessibility is defined as the number of opportunities within acceptable reach of a given place (Te Brömmelstroet, Curtis, Larsson, \& Milakis, 2016), where acceptable could refer to either a user perspective (section 2.1) or an environmental perspective (section 2.2). The objective of the analysis determines the relevant perspective as well as the appropriate operationalization of accessibility.

\subsection{The user perspective}

The user perspective is centered on how (potential) travelers experience accessibility. There are different manifestations of this viewpoint in how accessibility is conceptualized and measured. In fact, it can be related to all four components of accessibility, as defined by Geurs and Van Wee (2004): the land use, transportation, temporal, and individual component.

One central aspect of the land use component is the spatial distribution of destinations, representing relevant activities or opportunities (Handy \& Niemeier, 1997; Páez et al., 2012). Different types of opportunities can be analyzed, most of which are assumed to provide some benefit to individuals (e.g., job opportunities). Destination potentials can be weighted by their attractiveness or value for the user and classified according to their characteristics, which make them particularly relevant (or irrelevant) for a specific group of travelers.

Much-cited papers describe the transportation component as determining the effort (Geurs \& Van Wee, 2004) or ease (Handy \& Niemeier, 1997) of traveling for an individual. Consequently, travel costs in accessibility measures are often purely internal, typically measured in travel time or generalized costs, as experienced by the traveler (Cheng $\&$ Bertolini, 2013). Such implementations are useful to analyze the attractiveness and affordability of different transport modes for the user (El-Geneidy et al., 2016).

A person's range of accessible opportunities might be reduced due to the limited time available in between activities that are fixed in space and time. The temporal component of accessibility represents these individual spatial-temporal constraints (Geurs \& Van Wee, 2004).

Handy and Niemeier (1997) criticize loose consideration of the user perspective, arguing that accessibility measures should be determined by the uses and perceptions of the travelers, rather than the assumptions of the analyst. This comes along with a need for more disaggregate measures, focusing on (groups of) individuals as the unit of analysis. The individual component of accessibility acknowledges that persons have different characteristics, capabilities, and preferences (Geurs \& Van Wee, 2004), enabling a more accurate depiction of the travelers' viewpoint. However, even in aggregate implementations, accessibility is typically operationalized from a user perspective, albeit based on what the analyst assumes reasonable rather than on the users' actual perceptions and preferences (Páez et al., 2012). Clearly, the user perspective is particularly suitable for social evaluations, whereas its applicability for 
environmental evaluations is limited. In order to build upon accessibility analysis for a much-needed reduction in transport-related emissions, a shift in perspectives is required.

\subsection{The environmental perspective}

Especially in recent years, objectives related to climate change and emission reductions have been given high political priority. This shift in priorities needs to reflect in methods aimed at supporting decisionmaking, such as accessibility analysis (Kinigadner, Büttner, \& Wulfhorst, 2019). Contrary to the user perspective, which focuses on internal costs and benefits of individuals, the environmental perspective focuses on the external costs of travel to be borne by the environment and society in general. The environmental perspective is often treated implicitly in accessibility analysis. For example, if accessibility levels by carbon-efficient modes match the accessibility levels by carbon-intensive modes from a user perspective, this is associated with more sustainable travel options (Benenson, Martens, Rofé, \& Kwartler, 2011; Bertolini, Le Clercq, \& Kapoen, 2005; Salonen \& Toivonen, 2013). However, such implementations are not tailored to greenhouse gas emission reduction objectives and do not explicitly consider the environmental costs of travel activities. In the following, two options for more directly introducing an environmental perspective into accessibility analysis are outlined.

The first option is to quantify environmental impacts as an outcome of accessibility analysis. The user perspective determines the relevant opportunities based on their attraction factor and the individual costs involved in reaching them. The environmental perspective evaluates the external costs associated with traveling to these opportunities. However, greenhouse gas emissions are not only influenced by characteristics of the land use and transport systems, but also by individual characteristics, such as gender, age or income (Barla, Miranda-Moreno, \& Lee-Gosselin, 2011). Consequently, a more solid and disaggregate behavioral basis is required for more accurate quantification of emissions or emission savings. Data requirements and complexity are clearly a downside of this approach, especially with increasing consideration of the individual component.

The second option for incorporating environmental impacts, in particular $\mathrm{CO}_{2}$ emissions, into accessibility analysis is to weight opportunities based on the environmental costs of travel. In other words, environmental impacts serve as an input for the calculation of accessibility levels rather than an output of user-based accessibility measures. Referring back to the four components of accessibility addressed in section 2.1, the shift in perspectives from the user to the environment occurs with respect to the transportation component. A user viewpoint might still be applied to the land use component in order to select relevant origins and destinations.

Even though $\mathrm{CO}_{2}$ emissions might to some extent influence travel choices (Salonen, Broberg, Kyttä, \& Toivonen, 2014), the environmental impacts of travel are not necessarily evident to the users and expected to be much less determining than internal costs, such as travel time. Clearly, this results in a loss of behavioral basis with respect to the operationalization of accessibility. However, the proposed approach makes it possible to define normative accessibility standards and compare these standards with the actual situation. In this paper, we distinguish between "descriptive" and "prescriptive" accessibility measures (Páez et al., 2012). In the first case, the analysis is based on realized or assumed travel behavior, typically informed by travel behavior statistics and surveys. In the second case, the implementation is based on normative definitions of how people should (be able to) travel, which is decoupled from observed behavior.

Instead of finding or assessing intervention options with respect to individual user benefits, accessibility indicators using emissions as the underlying travel costs help to explore climate impacts, thus serving the common good. Cui and Levinson (2018) demonstrate how accessibility-based approaches, which are not limited to internal travel costs but also include external travel costs, might affect the rank- 
ing of potential interventions in the land use and transport system. However, their results also show that a full cost assessment is still dominated by monetary costs and travel times, which might underestimate the value of emission savings. For this reason, we opted for a clear distinction between accessibility analysis based on user costs and accessibility analysis based on environmental costs. The following section illustrates the accessibility impacts of such a shift in perspectives, where travel time is used as a proxy for the user perspective and $\mathrm{CO}_{2}$ emissions represent the environmental perspective.

\section{$3 \quad$ Comparing carbon-based and travel-time-based accessibility}

\subsection{Study area and data}

Travel-time-based and carbon-based accessibility levels by car and transit are compared using the Munich Metropolitan Region (MMR) in southern Germany as a study area. The MMR is an alliance of multiple institutional entities, ranging from public bodies to industry and academia, who collaborate to address common issues such as mobility (Metropolregion München, 2020). Of around six million inhabitants, 1.5 million live in the city of Munich, which acts as geographical and functional core of the region. A map of the region, presenting the density of workers at their residential location, is shown in Figure 1.

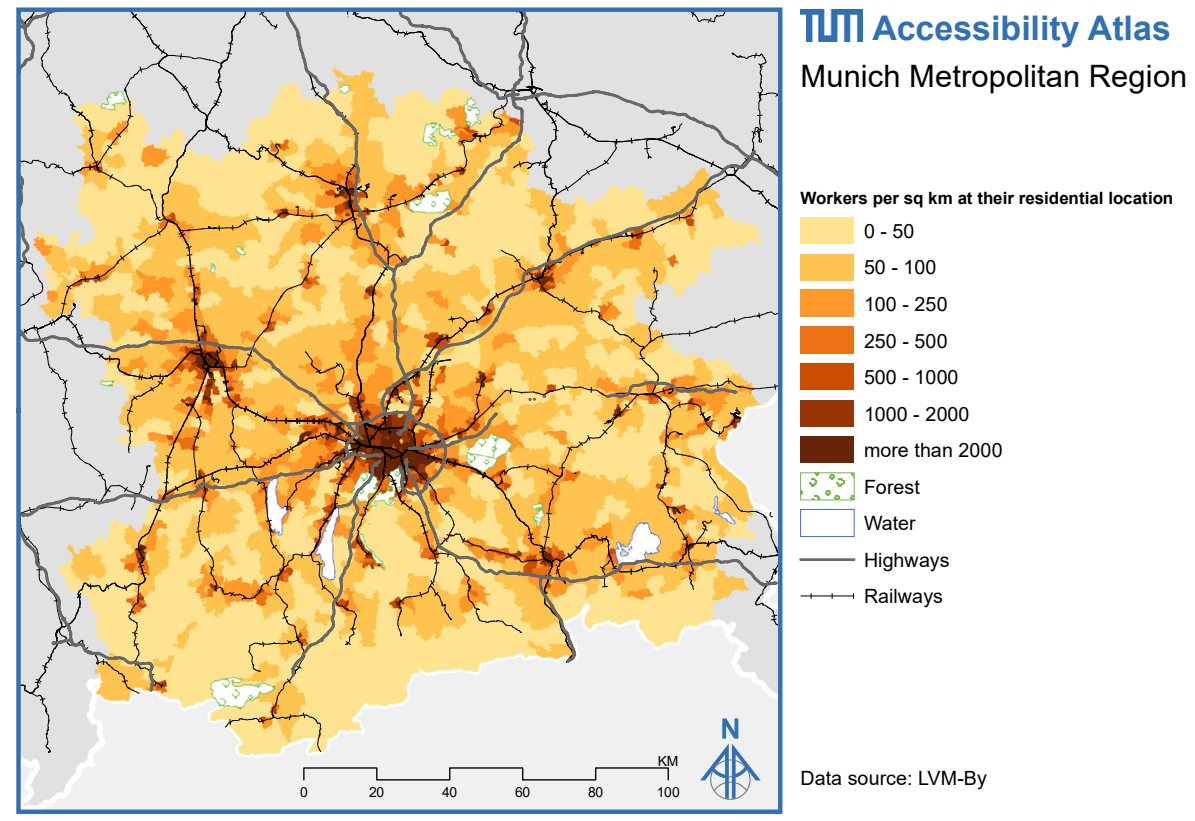

Figure 1. Density of workers in the MMR

Accessibility is analyzed on the spatial level of transportation analysis zones (TAZ). The main data source of the analysis is the official travel demand model of the state of Bavaria (LVM-By). The model is available in the transport modeling software PTV Visum and provides not only structural data on the TAZ level, but also transport networks as well as travel demand for both car and transit (Maget, Pillat, \& Waßmuth, 2019). Out of 6,659 TAZs in total, 1,918 are located within the MMR. Figure 2 provides an overview of the data, sources, and process used to calculate zone-to-zone travel times and emissions. 


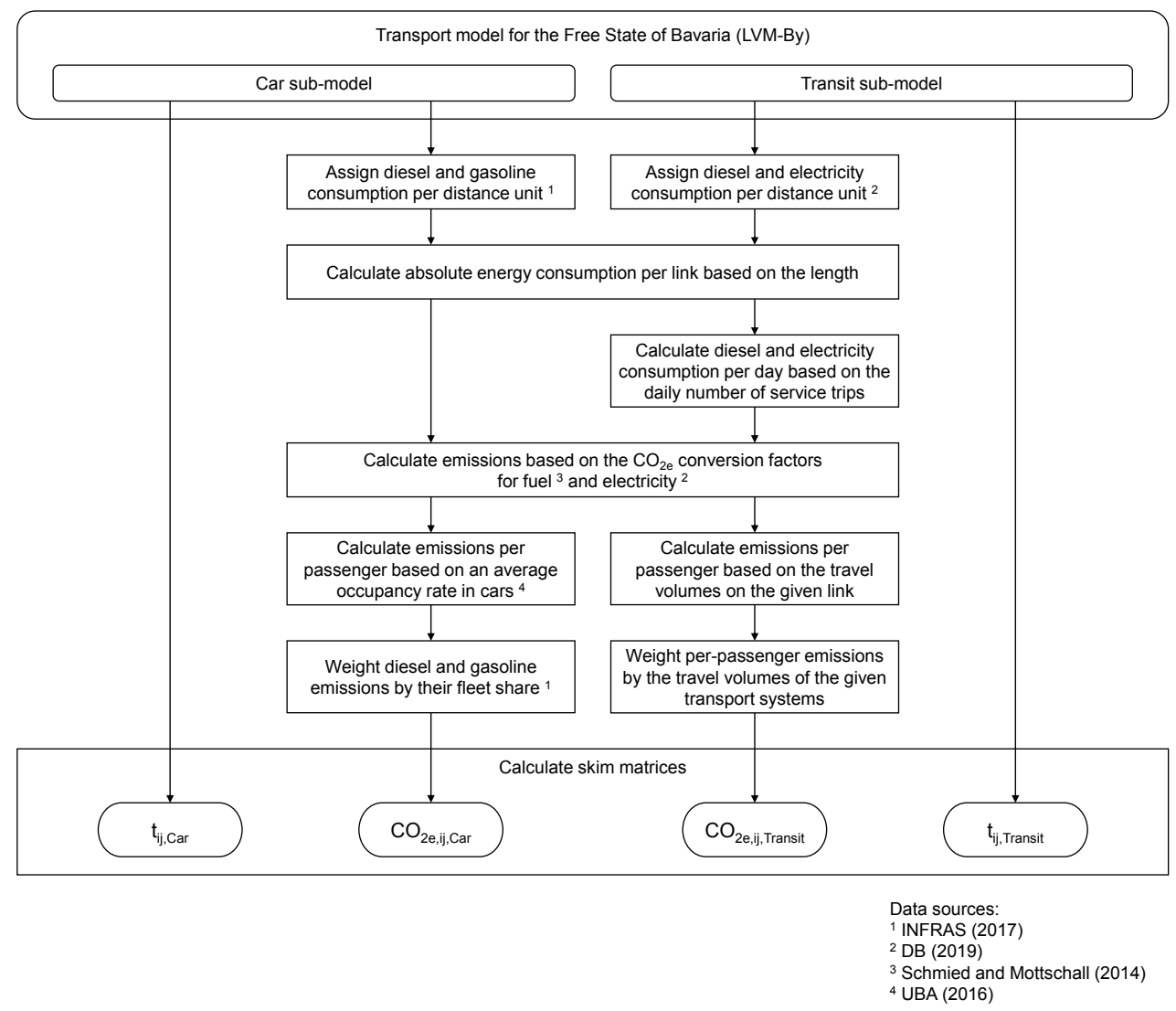

Figure 2. Process for calculating zone-to-zone travel time and emissions in the MMR

Zone-to-zone travel times by car and transit were directly calculated using a built-in procedure of PTVVisum. The retrieval of zone-to-zone $\mathrm{CO}_{2}$ emissions required editing of the networks as well as manipulation of the built-in skim matrix calculation. Different values for energy consumption per distance unit were assigned to all links in the car and transit networks, based on link characteristics which influence energy consumption. In transit, energy consumption varies by vehicle type and is given in liters of diesel for buses and kilowatt hours of electricity for trains, tramways, and subways. Since information on the precise vehicles in operation was unavailable, average energy consumption values for transit in Germany (DB, 2019) were assigned according to the transit route types given in the LVM-By. The relative fuel consumption of cars (in grams of diesel and gasoline per $\mathrm{km}$ ) was retrieved from version 3.3 of the Handbook Emission Factors for Road Transport (HBEFA, INFRAS, 2017). HBEFA is a comprehensive database which provides information on fuel consumption for different fuel types, years, and countries - in our case for the German fleet composition in 2018. Fuel consumption values per distance unit are available by traffic situation, which is determined by a combination of the following parameters: location (urban or rural), road type (e.g., national motorway or residential road), speed limit, and traffic state (free flow, dense, saturated, stop+go). Road type and speed limit are link attributes in the LVM-By car network. CORINE Land Cover, a dataset providing the shape and location of urban areas, was used to differentiate between urban and rural links. The traffic state was assumed to be saturated in urban areas and free flow in rural areas. Further analysis of the dynamics of carbon-based accessibility levels due to detailed spatial and temporal variations of traffic states represents an interesting perspective for future research, but requires high-quality congestion data. 
Relative values per kilometer were converted to absolute values based on the respective link lengths. Energy and fuel consumption were converted to carbon dioxide equivalents $\left(\mathrm{CO}_{2 \mathrm{e}}\right)$ using the corresponding conversion factors. For reasons of simplicity, we use the term $\mathrm{CO}_{2}$ in this paper, except for when we are speaking of mathematical units. For the car network, an average of diesel and gasoline emissions was calculated based on the German fleet composition in 2018. Since emission budgets would be assigned on a per-person basis, vehicle emissions were broken down to individual passengers based on occupancy rates. Occupancy rates in transit are derived from the LVM-By, which is capable of modeling daily passenger volumes by transit link and route. The occupancy rate of cars was uniformly set to 1.2, which represents a reasonable value for commutes (UBA, 2016). The emissions generated per person when traveling across the network links are used as travel cost attribute in the carbon-based accessibility analysis.

Four zone-to-zone matrices were calculated: travel time by car, travel time by transit, $\mathrm{CO}_{2}$ emissions by car, and $\mathrm{CO}_{2}$ emissions by transit. It should be noted that all calculations are based on an average of best paths between zones, as defined in the parameters of the LVM-By. Travel resistance in the car model is calculated based on travel time, including walking time and parking search time, as well as fuel costs. In transit, the relevant route choice parameters include travel time as the sum of walking, waiting, and in-vehicle travel time, as well as number of changes, fare, and service frequency. Travel time and $\mathrm{CO}_{2}$ emissions were accumulated along these best paths during the calculation. The resulting cost matrices were exported from the transport model in list format to be used for the accessibility calculation.

\subsection{Accessibility measures}

Independent of the underlying travel costs, there are numerous ways to operationalize accessibility. For the implementations presented in this paper, we selected a cumulative opportunities measure (Geurs \& Van Wee, 2004). The accessibility level is equal to the number of opportunities within a given travel cost threshold, in our case measured in terms of travel time and emissions, respectively. Equations (1) and (2) express this relation in mathematical terms:

$A_{i}=\sum_{j} D_{j} f\left(c_{i j}\right)$

$f\left(c_{i j}\right)=\left\{\begin{array}{l}1, \text { if } c_{i j} \leq \text { cutoff } \\ 0, \text { if } c_{i j}>\text { cutoff }\end{array}\right.$

The term $c_{i j}$ represents the travel costs that are generated when traveling from origin $i$ to destination $j$. Time and emission costs for all relevant zone-to-zone relations in the MMR are retrieved from the LVM-By. The term $D_{j}$ represents the destination potential at location $j$, in our case the number of workers at their residential location in each TAZ.

Cumulative opportunities measures are the simplest type of location-based accessibility indicators (Bertolini et al., 2005; Handy \& Niemeier, 1997). Nevertheless, this type of indicator offers an intuitively understandable approach to comparing travel-time-based and carbon-based accessibility levels by car and transit using the same unit, namely the number of workers within the given time and emission thresholds. The objective of the applications is not so much to deduce concrete recommendations for regional planning based on the analysis outcomes, but rather to illustrate the relative differences between the user perspective and the environmental perspective on accessibility. Further deliberation on the most suitable form of operationalization would certainly be necessary for real world applications.

Selecting an appropriate cutoff value represents the key calibration issue with cumulative opportunities measures (Handy \& Niemeier, 1997). In the following, we explain the reasoning behind our 
choice of threshold values for the comparison of travel-time-based and carbon-based accessibility landscapes. Three different specifications are used: a descriptive travel time budget based on current travel behavior, a descriptive $\mathrm{CO}_{2}$ emission budget based on current travel behavior, and a prescriptive $\mathrm{CO}_{2}$ emission budget if emission reduction targets are to become a reality.

1. Descriptive implementation from a user perspective: Travel time serves as the relevant travel cost in the accessibility analysis. Reasonable time thresholds are typically informed by travel survey statistics (Bertolini et al., 2005). The cutoff travel time in this application was chosen to be 28.6 minutes, which is the average travel time for a commuting trip in Germany (Follmer \& Gruschwitz, 2019).

2. Descriptive implementation from an environmental perspective: $\mathrm{CO}_{2}$ emissions serve as the relevant travel cost in the accessibility analysis. Similar to the travel time cutoff, the reasonable emission limit is based on current travel behavior. Commuting-related $\mathrm{CO}_{2}$ emissions can easily be estimated based on trip length and specific emission factors. Both of these parameters, and consequently emissions, are expected to be more heterogeneous across transport modes than travel times (even though transit users might also accept longer travel times than car drivers). Since the analysis is conducted for two motorized means of travel, namely car and transit, an average commuting trip by car was chosen as the benchmark. Specific emission factors in transit tend to be lower, but are more difficult to determine due to variations in occupancy rates. At the same time, trip lengths in transit tend to be longer, which counteracts the effect of lower per-passenger emissions to some extent. The starting point for estimating the $\mathrm{CO}_{2}$ cutoff value was the average trip length of a work trip by car in Germany, which is $18.4 \mathrm{~km}$ (BMVI, 2017). Based on average fuel consumption (INFRAS, 2017), the well-to-wheels emission factors of gasoline and diesel (Schmied \& Mottschall, 2014), as well as information on the German fleet composition (INFRAS, 2017), we deduced an average emission factor of around 190 grams of $\mathrm{CO}_{2 \mathrm{e}}$ per vehicle kilometer. Multiplying the emission factor by the trip length and dividing by the average occupancy yields a reasonable emission threshold of around 3,000 grams of $\mathrm{CO}_{2 e}$. We acknowledge that the average $\mathrm{CO}_{2}$ emissions across all commuting trips in Germany are certainly lower due to the share of less carbon intensive modes.

3. Prescriptive implementation from an environmental perspective: Again, $\mathrm{CO}_{2}$ emissions serve as the relevant travel cost in the accessibility analysis. The cutoff value is normatively defined and derived from emission reduction targets. Germany aims to reduce transport-related greenhouse gas emissions by at least 40\% compared to 1990 levels (BMU, 2016). Since the transport sector has not achieved any emission reductions so far, this percentage is still valid today (BMU, 2019). Applying this percentage to a one-way commute reduces the emission budget from 3,000 grams to 1,800 grams of $\mathrm{CO}_{2 \mathrm{e}}$. Emission budgets could also be derived from more nuanced considerations, for example in terms of the specific shares of the overall emission reductions to be borne by car users in particular. Car drivers will likely need to contribute more to the overall emission reductions than the users of other transport modes, because of their larger contribution to overall emissions. The $\mathrm{CO}_{2}$ emission budget used in this paper serves as a proxy and could be substituted by any normatively defined value. Besides the lower emission budget, all other parameters in the land use and transport system remain unchanged in the 2030 scenario. We acknowledge that by 2030, certain development, such as changed land use configurations, infrastructure changes, and changes in vehicle efficiency or fleet composition, will likely have taken place. The 2030 scenario is purely illustrative, intended to highlight needs for active intervention under current conditions, without taking any trends or actions as given.

Accessibility by car and transit is analyzed for each of the three implementations, resulting in a total of six accessibility landscapes. For reasons of comparability, the same thresholds were used for car 
and transit. Accessibility measures based on the given specifications were calculated using python scripts (Vale, 2019) and visualized in ArcGIS. The resulting accessibility landscapes in the MMR are presented in the following section.

\subsection{Accessibility landscapes}

\subsubsection{Spatial patterns}

The maps in Figure 3 show the results of the accessibility analysis. The same quantity classes were used for all implementations in order to be able to compare accessibility levels across maps. The spatial patterns in all maps have several commonalities. The larger cities feature high accessibility levels, whereas the peripheral areas in between the transport axes have lower accessibility to workers. Rural and mountainous areas, which can for example be found towards the alps in the south, show the lowest accessibility levels overall. Most workers can be reached by potential employers in dark colored TAZs, which are mainly found in the city of Munich.

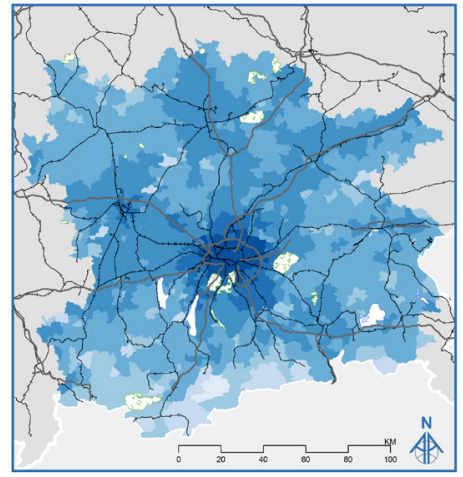

(a) Car travel time (threshold: $28.6 \mathrm{~min}$ )

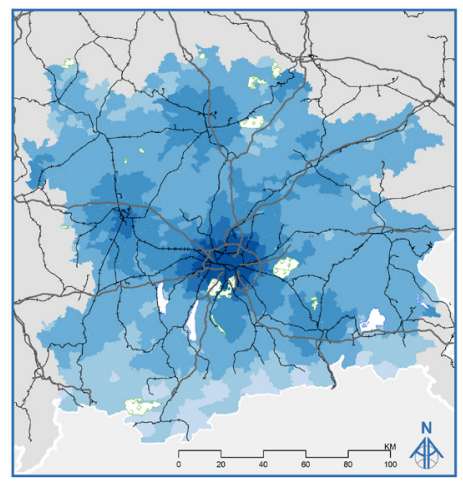

(c) $\mathrm{Car} \mathrm{CO}_{2} 2019$ (threshold: 3,000 grams)

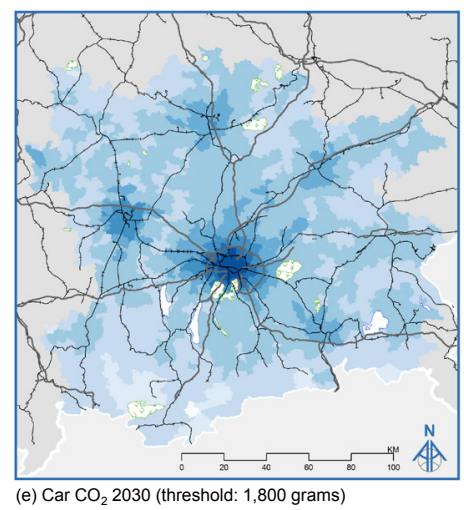

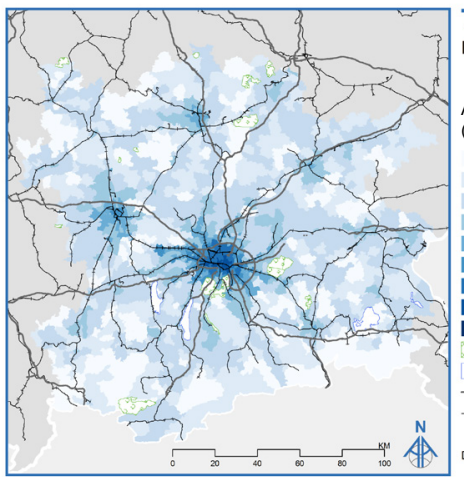

(b) Transit travel time (threshold: $28.6 \mathrm{~min}$ )

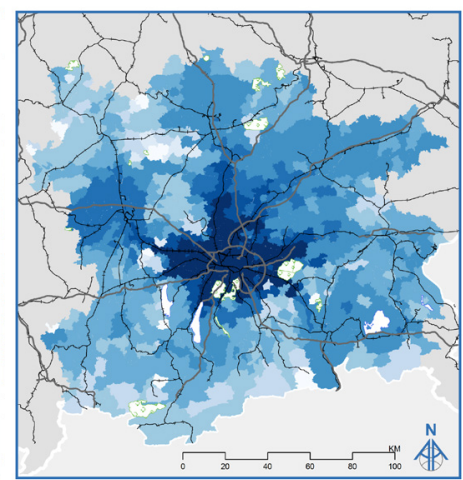

(d) Transit $\mathrm{CO}_{2} 2019$ (threshold: 3,000 grams)

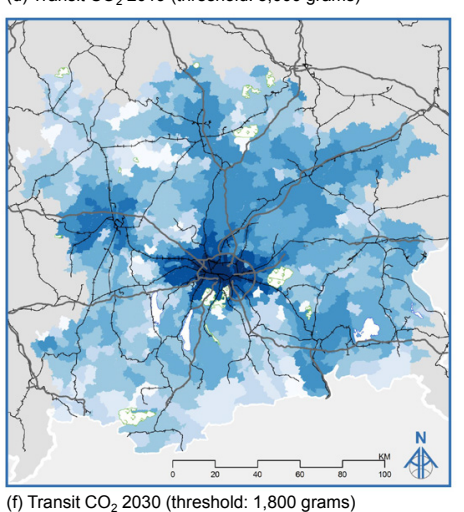

ITI Accessibility Atlas Munich Metropolitan Region

Accessibility to workers (absolute number)

$0-5,000$

$5,000-10,000$

$10.000-25,000$
$25,000-50,000$

$25,000-50,000$

$100,000-250,000$

$250,000-500,000$
$500,000 \cdot 1,000,000$

$500,000 \cdot 1,000,000$

Forest

- Highways

Thans

Figure 3. Travel-time-based and carbon-based accessibility by car and transit 
These general patterns are not surprising, as they match the population distribution and the radial transport network structure in the Munich metropolitan region. One noticeable particularity of the spatial patterns stems from the influence of occupancy rates on carbon-based accessibility by transit. According to the LVM-By, the northwest-southeast railway axis and the railway lines leading northwards have the largest passenger loads. This fact is evident in the maps as well, since Figure $3 \mathrm{~d}$ and Figure $3 \mathrm{f}$ have high carbon-based accessibility in the areas adjacent to these railway axes.

Despite some similarities in terms of relative spatial patterns, absolute accessibility levels are clearly different across maps, epitomized by the variations in color. The map for travel-time-based accessibility by transit is dominated by pale color shades, featuring the lowest accessibility levels among all implementations. Consequently, the visual difference between transit and car is dramatic when comparing the accessibility maps using the same travel time cutoff. Interestingly, this picture is reversed when focusing on carbon-based accessibility. Applying an emission budget rather than a time budget substantially increases transit accessibility. Transit outperforms car accessibility with both the 2019 and the 2030 $\mathrm{CO}_{2}$ emission cutoff. The highest overall accessibility levels, with more than one million workers within reach, are achieved in these two implementations. There is a striking difference between the transit accessibility maps using 28.6 minutes and 3,000 grams of $\mathrm{CO}_{2}$ as threshold values. Conversely, the two car accessibility maps based on these thresholds are nearly identical. This analogy in terms of absolute accessibility levels is excepted, since the 2019 emission budget is based on an average commuting trip by car. Consequently, the range is comparable to the average travel time per commuting trip. Carbon-based accessibility by car with the 2030 threshold (Figure 3e) performs just slightly better than travel-timebased accessibility by transit, with significant accessibility losses compared to the other two car accessibility implementations. Contrary to transit, occupancy rates in cars are generally independent of the spatial context, thus not reflecting in terms of spatial accessibility patterns. The carbon-based accessibility by car has a more polycentric pattern compared to travel-time-based accessibility, and urban cores stand out as high-accessibility islands.

\subsubsection{Cumulative distribution of accessibility values}

The visual trends observed in the previous section are underpinned by the empirical cumulative distribution function in Figure 4. Each accessibility implementation corresponds to one line, where the curve represents the share of accessibility values below the percentage of the overall maximum accessibility given on the horizontal axis. The cumulative percentage of travel-time-based accessibility by transit rises quickly at comparably low accessibility values. Carbon-based accessibility by car with the 2030 threshold has a similar curve, with slightly higher accessibility levels. The two remaining car accessibility implementations, namely travel-time-based accessibility and carbon-based accessibility with the 2019 limit, have almost identical curves. Carbon-based accessibility by transit with the more ambitious 2030 budget provides accessibility levels similar to these two implementations. However, the maximum accessibility values are even higher, resulting in a more moderate rise in the cumulative percentage towards higher accessibility levels. Carbon-based accessibility by transit with the 2019 limit clearly features the highest accessibility levels overall, with a particularly flat curve for the upper 25 to $50 \%$ of accessibility values. 


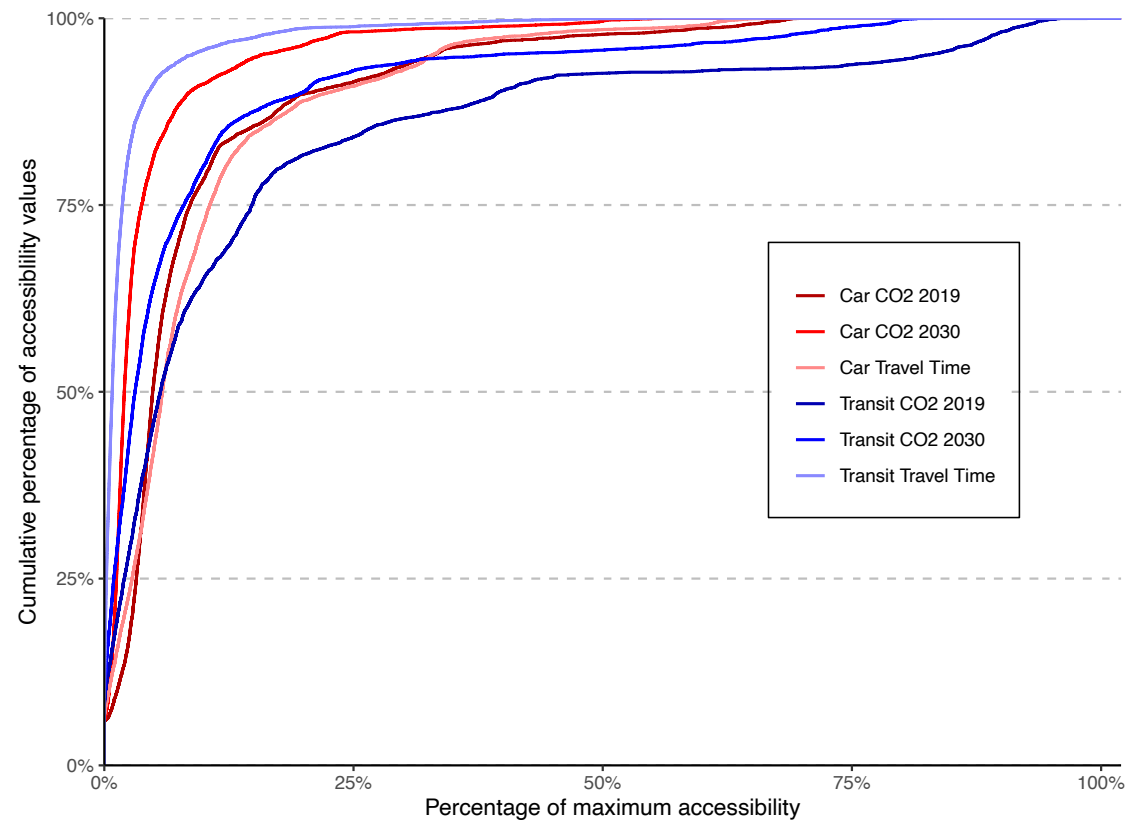

Figure 4. Cumulative distribution function of accessibility values

\subsubsection{Correlations between accessibility implementations}

Correlation matrices help to understand the relationship between two variables. Correlations between different implementations of accessibility in the same study area are typically high (Higgins, 2019). Figure 5 shows the correlations between the six different accessibility implementations for two different methods. The Pearson method (a) analyzes the linear relationship between two variables based on their values. The Spearman method (b) uses ranks instead and examines whether two variables increase or decrease together, independent of the rate of change. A correlation value close to 1 indicates that high values in the first array correspond to high values in the second array and vice versa. All correlations were found to be significant. Correlations are generally high (around $90 \%$ ) between the accessibility levels by car, independent of the specific travel cost used as threshold. This is not true for accessibility by transit, where only the measures using $\mathrm{CO}_{2}$ emissions as a travel cost have a correlation value above $90 \%$. The lowest correlation can be found between travel-time-based accessibility by transit and carbon-based accessibility by transit (2019), with a value of 59\% for the Pearson method. 


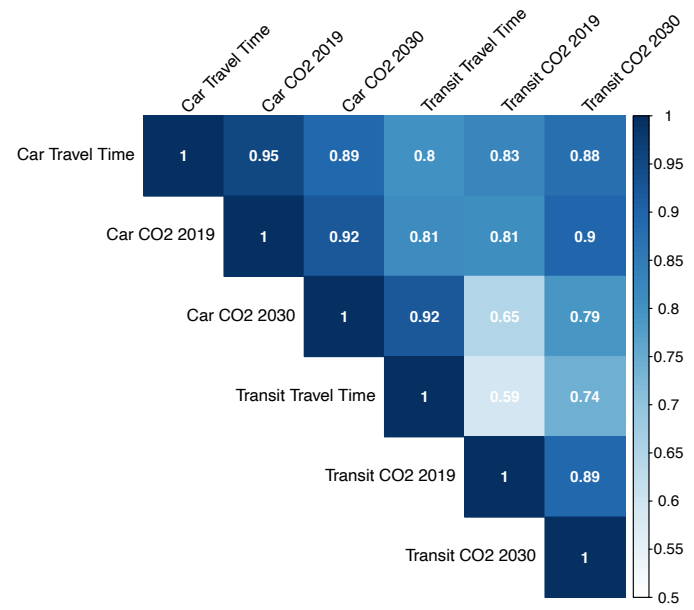

(a) Pearson

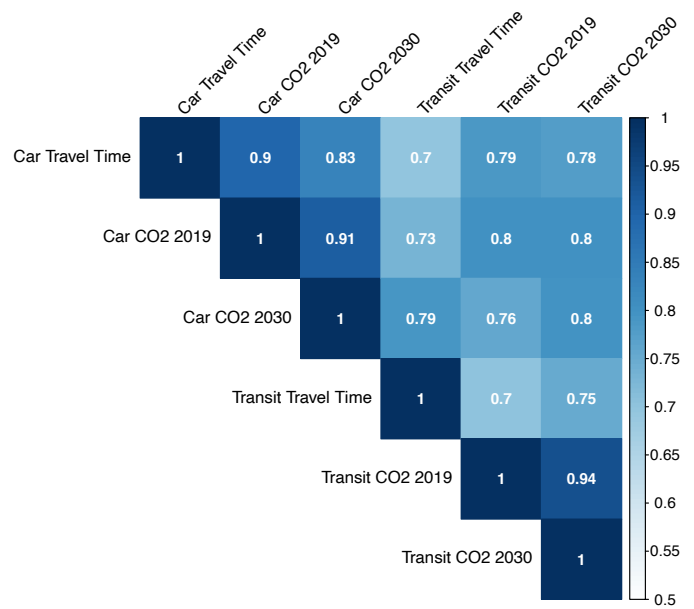

(b) Spearman

Figure 5. Correlations between accessibility levels

A corresponding scatter plot revealed that low values in terms of travel-time-based accessibility mainly correspond to low values in terms of carbon-based accessibility, but might also be paired with rather high carbon-based accessibility levels. This underlines the disconnect between travel-time-based and carbon-based accessibility by transit, as highlighted in the visual accessibility landscapes. Despite strong correlations of more than $70 \%$ for most variable pairs, there clearly seem to be dissimilarities pointing towards the fact that carbon-based accessibility highlights different aspects of the land use and transport systems compared to travel-time-based accessibility.

\subsubsection{Relative difference between car and transit}

Relative differences can be used to analyze the spatial disparities between two accessibility implementations rather than their relationship, as done in the correlation analysis. In this section, relative differences are calculated and mapped in order to compare the accessibility by car and transit for the different travel costs and thresholds. The relative difference (RD) for TAZ $\mathrm{i}$ is calculated according to Equation (3):

$R D_{i}=\frac{A_{i, a}-A_{i, b}}{A_{i, a}+A_{i, b}}$

The subscripts $a$ and $b$ indicate different accessibility implementations, for example travel-timebased accessibility by car and travel-time-based accessibility by transit. If both values are balanced, the relative difference is close to 0 . It approaches +1 if $A_{i, a}$ is large compared to $A_{i, b}$ and -1 if $A_{i, a}$ is small compared to $A_{i, b}$.

The relative differences between accessibility by car and transit on travel-time-based and carbonbased accessibility measures are shown in Figure 6. Throughout the region, the car enables access to a larger number of workers than transit when using time as the relevant travel cost (Figure 6a). This situation is reversed in the case of carbon-based accessibility, with nearly identical spatial patterns for the 2019 and 2030 thresholds (Figure 6b and Figure 6c). In both cases, transit performs better, especially in proximity to railway lines and the areas surrounding larger cities. 


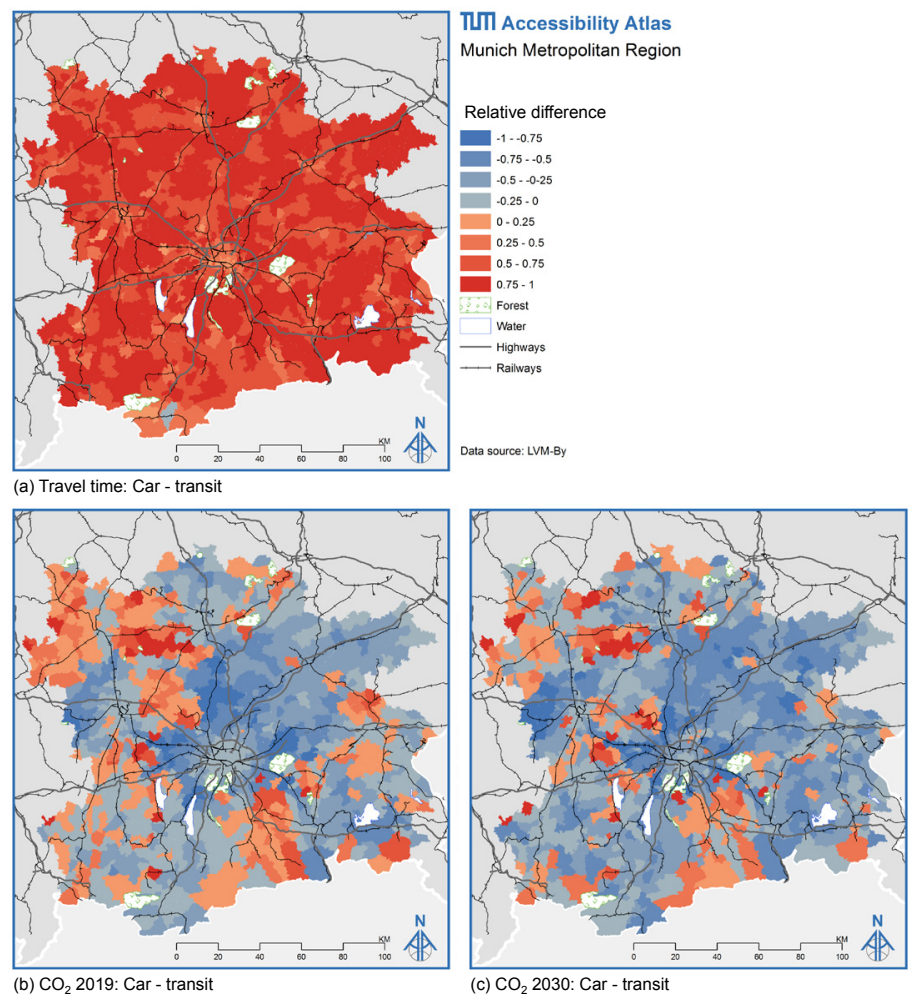

Figure 6. Relative differences: (Car - Transit)/(Car + Transit)

The northeastern part of the region, where carbon-based transit accessibility is generally high, stands out with primarily blue areas. Clearly, occupancy is a crucial determinant of how well transit performs against the car. The areas where the LVM-By indicates high occupancy rates, resulting in low carbon mobility options by transit, are concurrent with negative relative differences. At the same time, low occupancy areas correspond to positive relative differences, which implies that transit performs worse than the car in terms of emissions. While the possibility of relating this generally known fact to specific spatial contexts is valuable, the implications might be misinterpreted. For example, the maps could be used to argue for the abolishment of transit in rural areas for environmental reasons. If implemented, such policies will result in car dependence and social exclusion of citizens without the ability to drive. Transit lines in rural areas might also serve as feeder services towards main lines, enabling high occupancy transit in the first place. Similarly, increases in service frequency - per se an improvement in terms of the quality of the transit system - might negatively affect carbon-based accessibility if passenger numbers do not increase accordingly. Nevertheless, the analyses might also help to develop and assess alternative solutions in low-density spaces, such as smaller, electrified vehicles instead of diesel buses, and demand-sensitive solutions instead of traditional bus services with fixed routes and schedules.

\subsubsection{Relative difference between emissions and travel time}

Equation (3) was used to calculate relative differences between carbon-based and travel-time-based accessibility by car and transit, respectively. The results are visualized in Figure 7 . The relative differences between travel-time-based and carbon-based accessibility with the 2019 threshold are moderate in the case of the car, with the majority of values slightly above or below 0 . In contrast, the majority of TAZs experience a decrease in the number of accessible workers when $\mathrm{CO}_{2}$ emissions with the 2030 cutoff 
are used as travel cost instead of time. These results are expected, since the $2019 \mathrm{CO}_{2}$ emission budget is based on current travel behavior, just like travel time, whereas the 2030 cutoff limits the travelers' range based on the $40 \%$ reduction objective. If emission reduction targets were to be proportionally applied to individual travel activities, commuters' emission budgets will be exhausted before their time budgets are.

Carbon-based accessibility surpasses travel-time-based accessibility by transit for both the 2019 and the 2030 emission cutoff. The largest increases can be observed in the areas that feature high absolute carbon-based accessibility levels. The immediate city centers are an exception, since many workers can be reached within the given travel time threshold, as well.

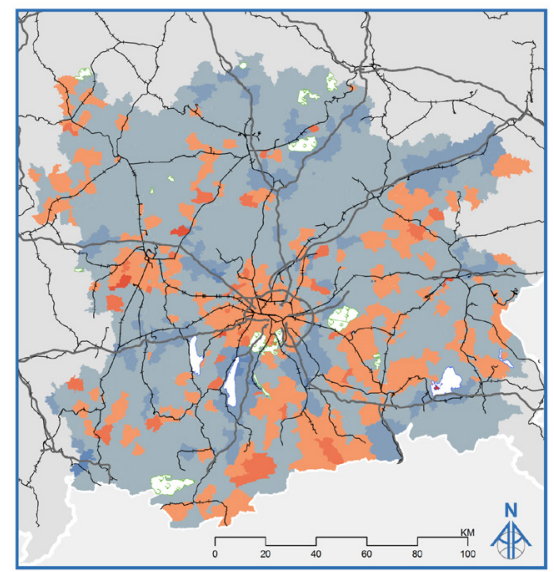

(a) Car: $\mathrm{CO}_{2} 2019$ - Travel time

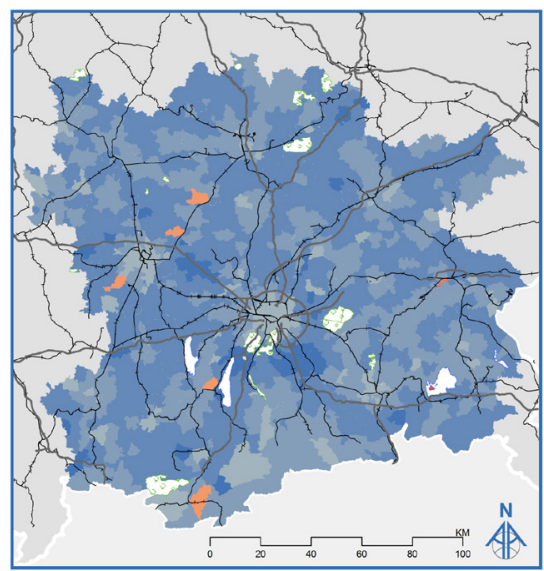

(c) Car: $\mathrm{CO}_{2} 2030$ - Travel time

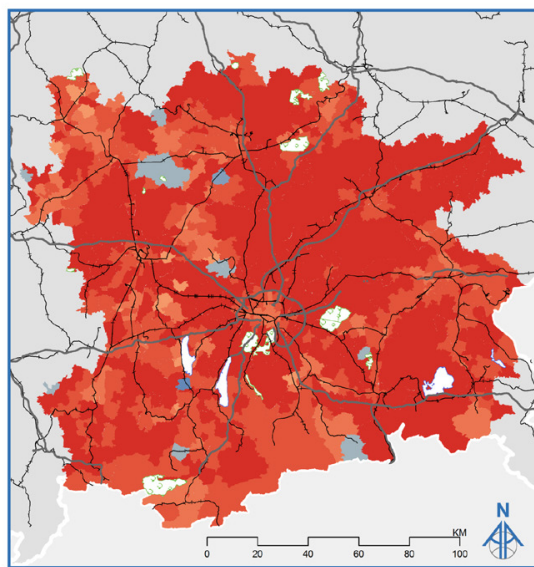

(b) Transit: $\mathrm{CO}_{2} 2019$ - Travel time

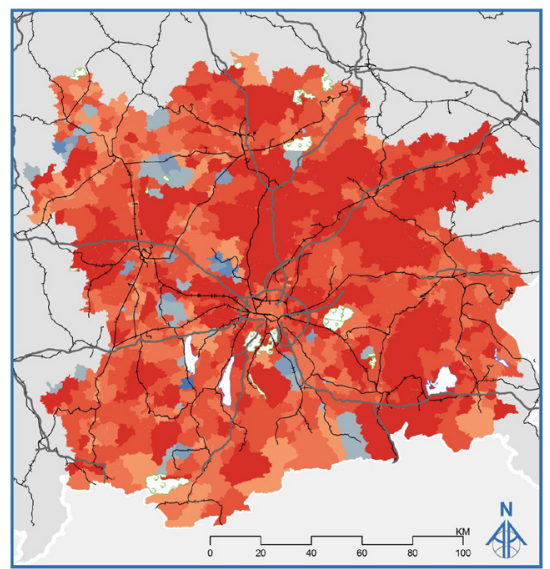

(d) Transit: $\mathrm{CO}_{2} 2030$ - Travel time
गाI Accessibility Atlas Munich Metropolitan Region

Relative difference

$-1--0.75$

$-0.75--0.5$
$-0.5--0.25$

$-0.5 \cdot-0-25$

0.0 .25

$0.25-0.5$

$0.5-0.75$

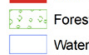

Highways

Data source: LVM-By

Figure 7. Relative differences: $\left(\mathrm{CO}_{2}-\right.$ Time $) /\left(\mathrm{CO}_{2}+\right.$ Time $)$

\subsubsection{Relative difference between emission cutoffs in 2019 and 2030}

A final useful application of relative differences is the comparison between the carbon-based accessibility landscapes with the 2019 and the 2030 budget. This analysis helps to identify areas that are most or least vulnerable to emission budgeting. Figure 8 highlights that accessibility losses are smallest in the cities, which is true for both car and transit. The effect on many peripheral regions in between the transport axes is small to moderate. This can be explained by generally low carbon-based accessibility levels with large distances to dense urban areas. Suburban areas are most affected by stricter emission limits, since the city cores are out of reach when reducing the emission budget. Dark shaded areas, indicating large accessibility losses, form a belt around the city of Munich in Figure 8b. As a consequence, decision-makers might need to focus their efforts for low carbon land use and transport interventions in these areas. 


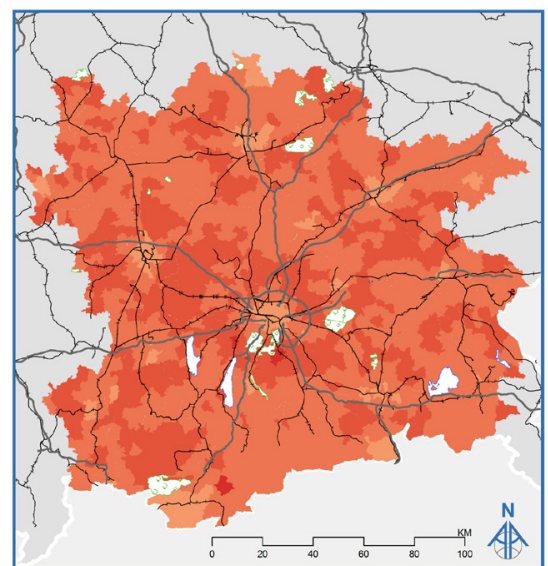

(a) Car: $\mathrm{CO}_{2} 2019-\mathrm{CO}_{2} 2030$

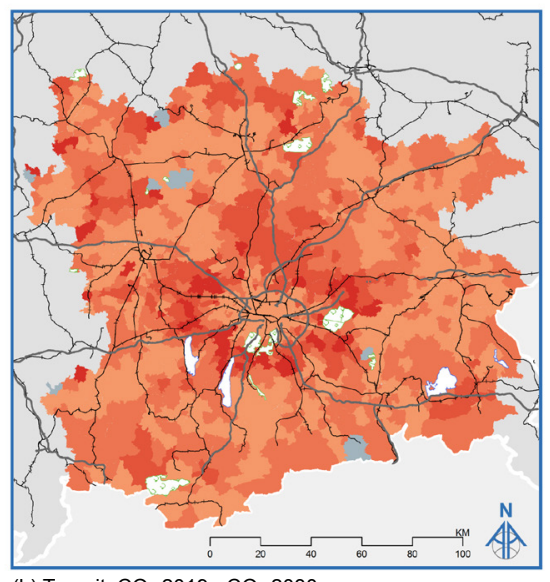

(b) Transit: $\mathrm{CO}_{2} 2019-\mathrm{CO}_{2} 2030$
TाI Accessibility Atlas Munich Metropolitan Region

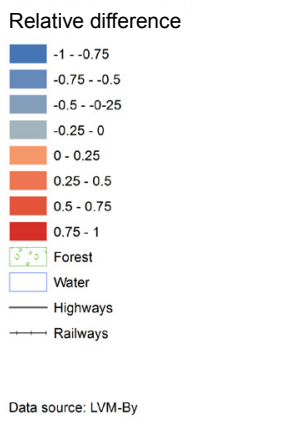

Figure 8. Relative differences: $\left(\mathrm{CO}_{2} 2019-\mathrm{CO}_{2} 2030\right) /\left(\mathrm{CO}_{2} 2019+\mathrm{CO}_{2} 2030\right)$

While the planning implications of the presented results are purely illustrative, carbon-based accessibility analysis might contribute to real-world planning issues. Potential applications, strengths and limitations are discussed in the following section.

\section{$4 \quad$ Carbon-based accessibility: A valuable contribution?}

This section discusses potential decision-making purposes for which carbon-based accessibility analysis could be useful. Particular focus is put on the added value compared to traditional accessibility analysis, which applies a user perspective on travel costs rather than an environmental perspective. Carbon-based and travel-time-based accessibility landscapes show different patterns, which supports the claim that they prioritize different planning goals.

In general, accessibility analysis serves two types of planning purposes (compare Bertolini, 2017). Firstly, it helps to analyze the current land use and transport situation in order to identify accessibility deficits or highlight development options. Secondly, it enables an assessment of the impacts of potential interventions in the land use and transport systems in order to prioritize, select or validate solutions. Carbon-based accessibility analysis in particular could thus help to identify and assess interventions related to the provision of low carbon mobility options. The following list of potential use cases is not necessarily exhaustive, but alludes to the variety of increasingly relevant planning questions, which could be addressed by carbon-based accessibility analysis.

- Identify intervention needs to provide for low carbon mobility options: The analysis in section 3 highlights large gaps between descriptive and prescriptive accessibility levels. Some areas stand out with particularly low carbon-based accessibility or high vulnerability to the introduction of emission budgets. Consequently, such analyses could be a starting point to identify and prioritize intervention needs, ensuring low carbon mobility options at existing settlements. On a more general level, the analysis highlights the dissimilarities between personal travel time budgets and per-capita emission budgets in a striking way. Consequently, planners need to identify and implement solutions that are able to align the environmental perspective and the user perspective on acceptable travel costs.

- Guide land use development based on the potential carbon footprint: Investment decisions might increasingly be determined by the potential carbon footprint of transport activities related to 
the location under consideration for development. Carbon-based accessibility analysis enables a comparison across urban structures, where locations could be classified based on the extent to which they provide low carbon mobility options. While these considerations help to guide urban development, other factors, such as the capacity of the existing transport system, need to be considered as well. For example, solely investing in locations with the highest carbon-based accessibility levels might lead to uneven utilization and overcrowding of the transit system.

- Strengthen environmental objectives in transport investment decisions: Environmental impacts should be explicitly considered in decision-making, as to not mask their importance. Traveltime-based evaluations suggest that time is the key optimization criterion. Efficiency improvements do not reflect in a corresponding accessibility map. On the contrary, carbon-based accessibility is sensitive to changes in occupancy or vehicle efficiency due to the underlying transport system parameters. Furthermore, whereas the car typically performs better than transit in terms of travel time, the picture is reversed when considering emissions. Investments in the transit system are expected to have a much larger positive impact on carbon-based accessibility than road extensions, depending on the spatial context and the efficiency of the vehicle fleet. Thus, this type of analysis could be useful for transit operators in order to argue for or assess the benefits of transit improvements in line with the existing urban patterns. Even though project appraisal certainly needs to consider multiple dimensions, the option to build a variety of low carbon mobility scenarios is expected to be a major strength of carbon-based accessibility planning.

- Support policies related to carbon pricing and budgeting: Emission pricing and carbon taxes are repeatedly discussed in the context of climate change mitigation. Carbon-based accessibility could easily be extended to address these topics. For example, taxes to be paid by land developers might depend on carbon-based accessibility. It is also likely that the users themselves will be charged for the emissions linked to their travel behavior. The analysis can be adapted to highlight the minimum price for reaching a fixed number of opportunities or the closest facility of a given kind. This in turn could directly be linked to social considerations and transport affordability. In the future, strict emission caps might not only apply to firms, but also individuals, introducing restrictions with regards to opportunity choices and transport mode choice. Consequently, frequent travelers would need to buy emission allowances from fellow residents with less carbon-intensive mobility behavior. The visualization of emission catchments would add transparency in terms of people's spatial range with a given $\mathrm{CO}_{2}$ budget. Interactive tools utilizing carbon-based accessibility could help citizens to plan for their individual radius of movement. In theory, the concept enables inclusion of longer leisure or business trips, but this requires an extension to supra-regional scales.

Despite a clear application potential of carbon-based accessibility, there are also limitations. Carbon-based accessibility only helps to plan for low carbon mobility options, whereas transport-related emissions are directly linked to realized mobility behavior. Traditional accessibility measures, focusing on the user view of the transport component, are more suitable to predict emission-relevant characteristics of this behavior, such as trip length or mode choice (Barla et al., 2011). Even if in theory the land use and transport conditions enable low carbon mobility, the realized behavior is not necessarily the same as the required behavior. Individuals need to embrace the low carbon mobility options provided through land use and transport planning by changing their attitudes and behavior. Carbon-based accessibility is unable to either assess strategies targeted at behavioral change or reflect the environmental impacts of behavioral change. Thus, the level of goal achievement related to emission reductions in the transport sector cannot be evaluated. Some hope in this regard lies in the communicative power attributed to accessibility instruments. The ability of carbon-based accessibility to visualize the impacts of transportrelated emissions in a specific spatial context could be a basis for the development of tools aimed at raising awareness among citizens. However, the verification of this and other hypotheses related to the 
practical relevance of carbon-based accessibility, which were raised in this section, is beyond the scope of this paper and needs to be addressed in future work.

\section{$5 \quad$ Conclusions and research perspectives}

In this paper, we compared accessibility implementations based on different perspectives on the transport component of accessibility. Travel costs from the user perspective were represented by travel time, whereas travel costs from the environmental perspective were represented by $\mathrm{CO}_{2}$ emissions. The emission thresholds of the cumulative opportunities indicator were based on both descriptive and prescriptive travel cost budgets. In light of the need to reduce transport-related greenhouse gas emissions, the latter, purely normative approach to implementing carbon-based accessibility might serve as an important indicator for decision-making. Carbon-based accessibility implementations are able to project $\mathrm{CO}_{2}$ emissions, a hardly tangible and barely perceptible global issue, onto specific local contexts in a visually striking way. The presented accessibility landscapes highlight disparities between locations, transport modes, and travel cost budgets. The results emphasize the magnitude of change needed and give support to the assumption that carbon-based accessibility brings added value to decision-making processes. Clearly, the selected emission budget determines the results of carbon-based accessibility analysis, where a more ambitious emission reduction target will cause accessibility losses, unless there are counteracting interventions in the land use and/or transport system. This trait is considered a major strength of the method and despite missing links with actual travel behavior, the concept offers a clear application potential in the context of planning for low carbon mobility options.

Carbon-based accessibility analysis and planning opens up multiple research paths to further explore, improve, and expand the method. Scenario-building capabilities were not tested in this paper, but represent an interesting starting point for future work. Carbon-based accessibility landscapes do not only change depending on the emission budget, but also react to interventions in both the land use and transport systems. The presented method can be used to assess the impacts of different urban development options on carbon-based accessibility. Structural interventions in the transport system, such as network extensions, will also reflect in the results of carbon-based accessibility analysis, possibly providing new insights from a low carbon perspective. Furthermore, carbon-based accessibility analysis is sensitive to changes in occupancy rates or vehicle efficiency, e.g., due to electrification of cars and buses, which distinguishes the approach from travel-time-based accessibility. A comparison of different evaluation methods promises to be highly interesting. For example, transit investments and road infrastructure investments could be analyzed by means of carbon-based accessibility, travel-time based accessibility, and standard evaluation methods in transport planning. The outcomes would likely be different and certainly provide a useful basis for further discussion.

Besides applying the method to a number of different planning purposes, alternative ways of operationalizing carbon-based accessibility should be explored. These could be different types of locationbased accessibility indicators, such as distance-decay measures, or implementations uniting the user perspective and the environmental perspective. Emissions could be incorporated into implementations considering the individual component of accessibility in order to determine the necessary magnitude of change in terms of perceptions, carbon price or willingness to pay for emission reductions, so that emission outcomes would be in line with normatively defined thresholds. Approaches considering the individual component of accessibility also enable social evaluations related to carbon pricing. For example, the inclusion of $\mathrm{CO}_{2}$ emissions as a travel cost component could be used to compare the accessibility impacts for high-income and low-income persons under different carbon price scenarios. Furthermore, 
the carbon-based approach might be extended to conceptually different types of accessibility indicators. For example, person-based accessibility indicators could consider emission constraints instead of or in addition to time constraints. Emissions would act as an authority constraint, limiting the freedom of movement and activity participation of people (Hägerstrand, 1970).

Even though climate change mitigation is a central theme around the globe, travel activities cause other environmental impacts besides greenhouse gas emissions. Negative externalities include congestion, noise, and a number of different pollutants, such as nitrogen oxides. Expanding the method to include other impacts enables a more comprehensive analysis of environmental accessibility. Opening up the method for the integration of multiple perspectives also makes it possible to apply accessibility analysis to other objectives besides environmental ones. Accessibility approaches based on generalized costs, both internal and external, could present an alternative to classical cost-benefit-analysis (Cui \& Levinson, 2018, 2019). Such holistic approaches help to combine economic, social, and environmental goals. This type of analysis could even consider wellbeing as a combination of these dimensions on the individual level, with a particular focus on mobility-impaired people, children or the elderly. Short-term individual user needs might to some extent be in conflict with the long-term common good. Carbonbased accessibility planning, if properly implemented, can contribute to linking both objectives. However, if environmental objectives shall be the focus, as argued earlier in this paper, the analysis of $\mathrm{CO}_{2}$ emissions in an isolated manner might be valid and necessary by itself.

Efforts to enhance the method need to be in parallel with the involvement of potential users in order to ensure two interconnected aspects: Firstly, fulfillment of the information needs of decision-makers and secondly, proper embedding into decision-making processes. Specific requirements will likely differ by spatial context, institutional arrangements, and application purposes. The outcomes could be contrary: A very simple method might be sufficient or a more multifaceted method might be necessary. The involvement of potential users is crucial in order to determine the added value of the method compared to, but also in addition to, existing decision-making tools and planning support systems. Further exploration of carbon-based accessibility is certainly worthwhile and decision-making tools based on this concept might help to better plan for low carbon mobility in the future.

\section{Acknowledgements}

The work presented in this paper has been conducted within the project "Alpine Smart Transport and Urbanism Strategies." This project is co-financed by the European Regional Development Fund through the Interreg Alpine Space program. The authors would like to thank the editors and reviewers for their support and valuable comments to improve this paper. 


\section{References}

Banister, D. (2008). The sustainable mobility paradigm. Transport Policy, 15(2), 73-80. https:// doi:10.1016/j.tranpol.2007.10.005

Banister, D. (2011). Cities, mobility and climate change. Journal of Transport Geography, 19(6), 15381546.

Barla, P., Miranda-Moreno, L. F., \& Lee-Gosselin, M. (2011). Urban travel $\mathrm{CO}_{2}$ emissions and land use: A case study for Quebec City. Transportation Research Part D: Transport and Environment, 16(6), 423-428. https://doi:10.1016/j.trd.2011.03.005

Benenson, I., Martens, K., Rofé, Y., \& Kwartler, A. (2011). Public transport versus private car GISbased estimation of accessibility applied to the Tel Aviv metropolitan area. The Annals of Regional Science, 47(3), 499-515.

Bertolini, L. (2017). Planning the mobile metropolis. Transport for people, places and the planet. London: Palgrave.

Bertolini, L., Le Clercq, F., \& Kapoen, L. (2005). Sustainable accessibility: A conceptual framework to integrate transport and land use plan-making. Two test-applications in the Netherlands and a reflection on the way forward. Transport Policy, 12(3), 207-220.

BMU. (2016). Climate Action Plan 2050. Principles and goals of the German government's climate policy. Berlin: Federal Ministry for the Environment, Nature Conservation and Nuclear Safety.

BMU. (2019). Klimaschutz in Zahlen. Fakten, Trends und Impulse deutscher Klimapolitik. Berlin: Federal Ministry for the Environment, Nature Conservation and Nuclear Safety.

BMVI. (2017). Mobilität in Tabellen (MiT 2017). Retrieved from http://www.mobilitaet-in-deutschland.de/MiT2017.html

Büttner, B. (2017). Consequences of sharp increases in mobility costs on accessibility. Suggestions for individual and public development strategies (Ph.D. dissertation). Technical University of Munich, Munich.

Büttner, B., Ji, C., \& Wulfhorst, G. (2019). The TUM accessibility atlas: A tool for research and practice. In C. Silva, L. Bertolini, \& N. Pinto (Eds.), Designing accessibility instruments: Lessons on their usability for integrated land use and transport planning practices (pp. 120-131). New York: Routledge.

Chapman, L. (2007). Transport and climate change: A review. Journal of Transport Geography, 15(5), 354-367.

Cheng, J., \& Bertolini, L. (2013). Measuring urban job accessibility with distance decay, competition and diversity. Journal of Transport Geography, 30, 100-109. https://doi:10.1016/j.jtrangeo.2013.03.005

Cui, M., \& Levinson, D. (2018). Full cost analysis of accessibility. Journal of Transport and Land Use, 11(1) 661-679. https://doi:10.5198/jtlu.2018.1042

Cui, M., \& Levinson, D. (2019). Measuring full cost accessibility by auto. Journal of Transport and Land Use, 12(1), 649-672. https://doi:10.5198/jtlu.2019.1495

Curtis, C., \& Scheurer, J. (2010). Planning for sustainable accessibility: Developing tools to aid discussion and decision-making. Progress in Planning, 74(2), 53-106. https://doi:10.1016/j.progress.2010.05.001

DB. (2019). Grundlagenbericht zum UmweltMobilCheck. Retrieved from https://www.deutschebahn. com/resource/blob/4390084/aaf9ae78149111f1b772ed493736b258/grundlagenbericht-data.pdf

EEA. (2019). Annual European Union greenhouse gas inventory 1990-2017 and inventory report 2019. Retrieved from https://www.eea.europa.eu/publications/european-union-greenhouse-gas-inventory-2019

El-Geneidy, A., Levinson, D., Diab, E., Boisjoly, G., Verbich, D., \& Loong, C. (2016). The cost of equity: Assessing transit accessibility and social disparity using total travel cost. Transportation Research Part A: Policy and Practice, 91, 302-316. https:/doi:10.1016/j.tra.2016.07.003 
Follmer, R., \& Gruschwitz, D. (2019). Mobilität in Deutschland-MiD Kurzreport. Ausgabe 4.0. Retrieved from www.mobilitaet-in-deutschland.de

Ford, A., Dawson, R., Blythe, P., \& Barr, S. (2018). Land-use transport models for climate change mitigation and adaptation planning. Journal of Transport and Land Use, 11(1) 83-101. https:// doi:10.5198/jtlu.2018.1209

Geels, F. W. (2012). A socio-technical analysis of low-carbon transitions: Introducing the multi-level perspective into transport studies. Journal of Transport Geography, 24, 471-482.

Geurs, K., \& Van Wee, B. (2004). Accessibility evaluation of land-use and transport strategies: Review and research directions. Journal of Transport Geography, 12(2), 127-140.

Hägerstrand, T. (1970). What about people in regional science? Papers of the Regional Science Association, 24, 7-21.

Handy, S., \& Niemeier, D. (1997). Measuring accessibility: An exploration of issues and alternatives. Environment and Planning A, 29(7), 1175-1194.

Heinen, E., \& Mattioli, G. (2019). Multimodality and $\mathrm{CO}_{2}$ emissions: A relationship moderated by distance. Transportation Research Part D: Transport and Environment, 75, 179-196. https:// doi:10.1016/j.trd.2019.08.022

Higgins, C. D. (2019). Accessibility toolbox for R and ArcGIS. Transport Findings. https:// doi: $10.32866 / 8416$

INFRAS. (2017). HBEFA version 3.3. Retrieved from http://www.hbefa.net/e/documents/HBEFA33_ Hintergrundbericht.pdf

Kinigadner, J., Büttner, B., \& Wulfhorst, G. (2019). Beer versus bits: $\mathrm{CO}_{2}$-based accessibility analysis of firms' location choices and implications for low carbon workplace development. Applied Mobilities, 4(2), 200-218. https://doi:10.1080/23800127.2019.1572053

Kwan, M.-P. (1998). Space-time and integral measures of individual accessibility: A comparative analysis using a point-based framework. Geographical Analysis, 30(3), 191-216.

Lewis, R., Zako, R., Biddle, A., \& Isbell, R. (2018). Reducing greenhouse gas emissions from transportation and land use: Lessons from West Coast states. Journal of Transport and Land Use, 11(1), 343-366. https://doi:10.5198/jtlu.2018.1173

Loo, B., \& Tsoi, K. H. (2018). The sustainable transport pathway: A holistic strategy of five transformations. Journal of Transport and Land Use, 11(1), 961-980. https://doi:10.5198/jtlu.2018.1354

Maget, C., Pillat, J., \& Waßmuth, V. (2019). Transport demand model for the free state of Bavaria basis for local transport planning. Transportation Research Procedia, 41, 219-228.

Marsden, G., Ferreira, A., Bache, I., Flinders, M., \& Bartle, I. (2014). Muddling through with climate change targets: A multi-level governance perspective on the transport sector. Climate Policy, 14(5), 617-636.

Metropolregion München. (2020). Retrieved from https://www.metropolregion-muenchen.eu/

Ostrom, E. (2010). Polycentric systems for coping with collective action and global environmental change. Global Environmental Change, 20(4), 550-557. https://doi:10.1016/j.gloenvcha.2010.07.004

Páez, A., Scott, D. M., \& Morency, C. (2012). Measuring accessibility: Positive and normative implementations of various accessibility indicators. Journal of Transport Geography, 25, 141-153. https:// doi:10.1016/j.jtrangeo.2012.03.016

Papa, E., Silva, C., Te Brömmelstroet, M., \& Hull, A. (2016). Accessibility instruments for planning practice: A review of European experiences. Journal of Transport and Land Use, 9(3), 57-75. https:// doi:10.5198/jtlu.2015.585

Salonen, M., Broberg, A., Kyttä, M., \& Toivonen, T. (2014). Do suburban residents prefer the fastest or low-carbon travel modes? Combining public participation GIS and multimodal travel time 
analysis for daily mobility research. Applied Geography, 53, 438-448. https://doi:10.1016/j.apgeog.2014.06.028

Salonen, M., \& Toivonen, T. (2013). Modelling travel time in urban networks: Comparable measures for private car and public transport. Journal of Transport Geography, 31, 143-153. https://doi:10.1016/j. jtrangeo.2013.06.011

Schmied, M., \& Mottschall, M. (2014). Berechnung des Energieverbrauchs und der Treibhausgasemissionen des ÖPNV. Retrieved from https://www.bmvi.de/SharedDocs/DE/Anlage/G/energieverbrauch-treibhausgasemission-oepnv.html

Schwanen, T. (2019). Transport geography, climate change and space: Opportunity for new thinking. Journal of Transport Geography, 81(C). https://doi:10.1016/j.jtrangeo.2019.102530

Schwanen, T., Banister, D., \& Anable, J. (2011). Scientific research about climate change mitigation in transport: A critical review. Transportation Research Part A: Policy and Practice, 45(10), 993-1006.

Te Brömmelstroet, M. (2010). Equip the warrior instead of manning the equipment. Land use and transport planning support in the Netherlands. Journal of Transport and Land Use, 3(1), 25-41. https://doi:10.5198/jtlu.v3i1.99

Te Brömmelstroet, M., Curtis, C., Larsson, A., \& Milakis, D. (2016). Strengths and weaknesses of accessibility instruments in planning practice: Technological rules based on experiential workshops. European Planning Studies, 24(6), 1175-1196.

UBA. (2016). Fahrgemeinschaften. Retrieved from https://www.umweltbundesamt.de/umwelttippsfuer-den-alltag/mobilitaet/fahrgemeinschaften

UNFCCC. (2015). Paris Agreement. Retrieved from https://unfccc.int/process-and-meetings/the-paris-agreement/the-paris-agreement.

US EPA. (2019). Inventory of U.S. greenhouse gas emissions and sinks: 1990-2017. Retrieved from https:// www.eea.europa.eu/publications/european-union-greenhouse-gas-inventory-2019

Vale, D. S. (2019). Calculate-accessibility. Retrieved from https://github.com/davidsvale/calculate-accessibility

Vale, D. S., \& Pereira, M. (2016). The influence of the impedance function on gravity-based pedestrian accessibility measures: A comparative analysis. Environment and Planning B: Urban Analytics and City Science, 44(4), 740-763. https://doi:10.1177/0265813516641685

Wulfhorst, G., Büttner, B., \& Ji, C. (2017). The TUM accessibility atlas as a tool for supporting policies of sustainable mobility in metropolitan regions. Transportation Research Part A: Policy and Practice, 104, 121-136. 